\title{
Very High Cycle Fatigue Crack Initiation Mechanism in Nugget Zone of AA 7075 Friction Stir Welded Joint
}

\author{
Chao He, ${ }^{1,2}$ Kazuhiro Kitamura, ${ }^{3}$ Kun Yang, ${ }^{4}$ Yong-jie Liu, ${ }^{4}$ \\ Qing-yuan Wang, ${ }^{1,4}$ and Qiang Chen ${ }^{2}$ \\ ${ }^{1}$ School of Architecture and Civil Engineering, Chengdu University, Chengdu 610106, China \\ ${ }^{2}$ Micromechanics Laboratory, Faculty of Engineering, Kyushu University, Fukuoka 8190395, Japan \\ ${ }^{3}$ Department of Mechanical Engineering, Kochi National College of Technology, Nankoku 783-8508, Japan \\ ${ }^{4}$ Key Laboratory of Energy Engineering Safety and Disaster Mechanics, Ministry of Education, \\ Sichuan University, Chengdu 610065, China \\ Correspondence should be addressed to Qing-yuan Wang; wangqy@scu.edu.cn
}

Received 9 June 2017; Accepted 30 August 2017; Published 27 November 2017

Academic Editor: Pavel Lejcek

Copyright ( $\odot 2017$ Chao He et al. This is an open access article distributed under the Creative Commons Attribution License, which permits unrestricted use, distribution, and reproduction in any medium, provided the original work is properly cited.

\begin{abstract}
Very high cycle fatigue behavior of nugget zone in AA 7075 friction stir welded joint was experimentally investigated using ultrasonic fatigue testing system $(20 \mathrm{kHz})$ to clarify the crack initiation mechanism. It was found that the fatigue strength of nugget zone decreased continuously even beyond $10^{7}$ cycles with no traditional fatigue limits. Fatigue cracks initiated from the welding defects located at the bottom side of the friction stir weld. Moreover, a special semicircular zone could be characterized around the crack initiation site, of which the stress intensity factor approximately equaled the threshold of fatigue crack propagation rate. Finally, a simplified model was proposed to estimate the fatigue life by correlating the welding defect size and applied stress. The predicted results are in good agreement with the experimental results.
\end{abstract}

\section{Introduction}

High strength aluminum alloys are playing an increasingly important role in many engineering applications including transportation, aerospace, and electric communication, due to the pressing demand for lightweight structures to improve fuel efficiency and reduce $\mathrm{CO}_{2}$ emissions $[1,2]$. But the shortcomings of their weldability, such as poor solidification microstructure, porosity in the fusion zone, and softening in the heat affect zone, are among the major issues which are currently limiting their widespread applications $[3,4]$. For a long time, aluminum alloys were regarded as nonweldable using traditional arc welding, electron beam welding, or even laser welding, which needs research efforts for developing new innovative welding techniques. In 1991, friction stir welding (FSW) technique was invented by the welding institute (TWI) [5], and it was especially suitable for the jointing of aluminum alloy with the benefits of better retention of base material properties, fewer welding defects, and lower residual stresses [6]. As a solid state joining technique, the basic concept and processing of FSW are remarkably simple and can be detailedly found in some previous works [6-8].

Generally, the FSW joints used in automobile, aircraft, and railway industries are subjected to cyclic loading with up to $10^{9}$ cycles during their expected service life $[9,10]$. Therefore, very high cycle fatigue (VHCF) behaviors of FSW joints are of great interest for these applications. Deng et al. [11] reported that the VHCF fatigue strength of FSW joints was superior to that of the base material (AA 7075-T7451). It revealed that the fatigue crack originated at the advancing side due to the effects of microstructural heterogeneity. Our previous work $[12,13]$ also found that fatigue crack initiation sites were localized at the thermomechanically affected zone on the advancing side below $10^{8}$ cycles. Nevertheless, the failure was prone to occur at the nugget zone in the VHCF regime. This transition of fatigue failure location from the thermomechanically affected zone to nugget zone can probably be ascribed to the dynamic recrystallization 
TABLE 1: Chemical composition of 7075-T651 aluminum alloy (wt.\%).

\begin{tabular}{|c|c|c|c|c|c|c|c|c|c|c|}
\hline \multirow{2}{*}{$\mathrm{Cr}$} & \multirow{2}{*}{$\mathrm{Cu}$} & \multirow{2}{*}{$\mathrm{Fe}$} & \multirow{2}{*}{$\mathrm{Mg}$} & \multirow{2}{*}{$\mathrm{Mn}$} & \multirow{2}{*}{$\mathrm{Si}$} & \multirow{2}{*}{$\mathrm{Ti}$} & \multirow{2}{*}{$\mathrm{Zn}$} & \multicolumn{2}{|c|}{ Other impurities } & \multirow{2}{*}{$\mathrm{Al}$} \\
\hline & & & & & & & & Each & Total & \\
\hline $0.18-0.28$ & $1.2-2.0$ & 0.5 & $2.1-2.9$ & 0.3 & 0.4 & 0.2 & $5.1-6.1$ & 0.05 & 0.15 & Rest \\
\hline
\end{tabular}

TABLE 2: Mechanical properties of the 7075-T651 aluminum alloy.

\begin{tabular}{lccccc}
\hline As received & Ultimate strength $(\mathrm{MPa})$ & Yield strength $(\mathrm{MPa})$ & Modulus of elasticity $(\mathrm{GPa})$ & Poisson's ratio & Elongation $(\%)$ \\
\hline T651 & 486 & 453 & 72 & 0.33 & 13.9 \\
\hline
\end{tabular}

process during the FSW processing, which redistributed the particles in the nugget zone. Therefore, it can be seen that the fatigue strength of different subzones across the welds was inconsistent because of the microstructural heterogeneity, indicating that the fatigue test on the whole butt joint can only obtain the strength of the weakest zone. For a better understanding of the VHCF behaviors of FSW joints, it is essential to determine the local mechanical properties of different weld subzones. Especially for the nugget zone, it is more sensitive to the VHCF failure than other subzones.

The fatigue behaviors of FSW joints, including the fatigue crack propagation $[14,15]$, low cycle fatigue $[16,17]$, and high cycle fatigue [18], have been experimentally studied in many previous works. It was found that the FSW process had a positive effect on the fatigue properties of the joints. However, the fatigue crack initiation, which is the key factor to influencing and even determining the VHCF behaviors, is quite limited. In the present study, the local VHCF behaviors in the nugget zone of aluminum alloy FSW joint are experimentally investigated using ultrasonic fatigue testing system. Fatigue crack initiation mechanism is characterized by taking into account the microstructure heterogeneity and dynamic recrystallization process. Moreover, a model is developed for correlating the effect of defect size and applied stress on the fatigue life, and the predictions accord with the experimental results well.

\section{Materials and Experimental Procedures}

High strength aluminum alloy 7075-T651 rolled plates with $10 \mathrm{~mm}$ thickness were selected as jointing materials. The nominal chemical compositions and static mechanical properties of AA 7075 are listed in Tables 1 and 2, respectively. The weld experiment was performed on an FSW-LM-CM16 machine using a stir tool with a shoulder of $25 \mathrm{~mm}$ in diameter and a flat pin of adjustable length. The schematic diagram of the welding process is shown in Figure 1(a), in which the welding direction is perpendicular to the rolling direction. During the FSW process, the welding parameters used in this test are with a rotation speed of $300 \mathrm{rpm}$, a welding speed of $150 \mathrm{~mm} / \mathrm{min}$, and a tool tilt angle of $8^{\circ}$.

Both the top and root sides of the FSW plates with a thickness of $1 \mathrm{~mm}$ were skimmed to eliminate the effect of profile irregularities on stress concentration. The fatigue specimens are sectioned along the transverse direction of the welded plate with the nugget zone located at the semicircular gap. This gap can position the maximum stress in a local zone within the nugget zone due to the wave-like distribution of the applied stress so that the local fatigue behaviors of nugget zone could be determined. Figure 1(b) shows the detailed dimensions of ultrasonic fatigue specimen, which has a resonant frequency of $20 \mathrm{kHz}$ in the longitudinal direction. The surfaces of all specimens were subjected to electrolytic etching with perchloric acid/ethanol solution to reveal microstructure after a standard mechanical polishing. Fatigue test was conducted using an ultrasonic fatigue testing system (SHIMADZU USF-2000) at a frequency of $20 \mathrm{kHz}$. A detailed description of the principle of this highfrequency fatigue testing method can be found in a recent overview work [19]. In this work, ultrasonic fatigue test was performed at constant stress ratio $R$ of -1 , and compressed air-cooling was used to keep the increase of specimen surface temperature below $10^{\circ} \mathrm{C}$. After testing, fatigue crack initiation and propagation behaviors were carefully examined using scanning electron microscope (SEM) and optical microscope (OM).

\section{Experimental Results}

3.1. Microstructure. Optical image of the cross section in the transverse direction of the weld is shown in Figure 2(a). According to the microstructure characteristics, four different zones including base material (BM), heat affected zone (HAZ), thermomechanically affected zone (TMAZ), and nugget zone (NZ) can be clearly distinguished as shown in Figure 2(b). The BM presents large elongated lath-like grains with typical rolling morphology. In the HAZ, the shape and size of grains stay the same as the BM without any plastic deformation, but the material is softened owing to the coarsening of precipitates because of the influence of the thermal cycle. The grains in the TMAZ experience severe plastic deformation caused by the tool but are not recrystallized, so the grains exhibit an upward flowing pattern around the weld center. In the NZ, intense plastic deformation and heat input result in the generation of a recrystallized fine-grained microstructure. In addition, the average size changes of these equiaxed grains along the thickness direction in the NZ are summarized in Figure 2(c), in which the grain sizes near the top and bottom of the weld are $6 \mu \mathrm{m}$ and $3.5 \mu \mathrm{m}$, respectively. This indicates that the grain size tends to decrease from the top to bottom of the NZ. Such variation in grain size of the $\mathrm{NZ}$ is associated with the difference in heat dissipation in the nugget zone [6]. The bottom of plates is in contact with the backing plate that acts as a heat conductor, so the 


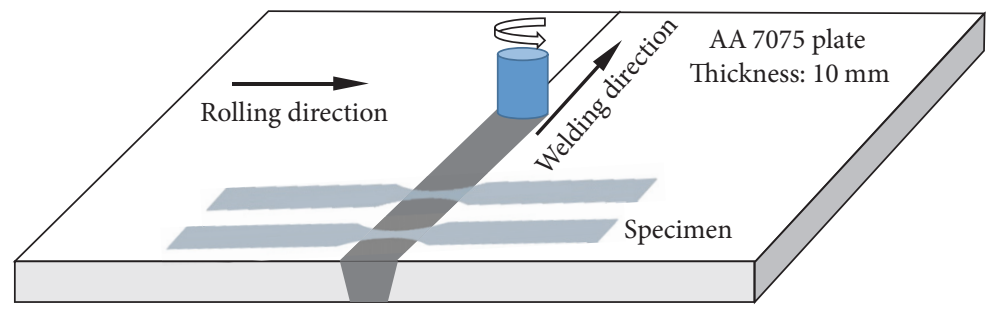

(a)

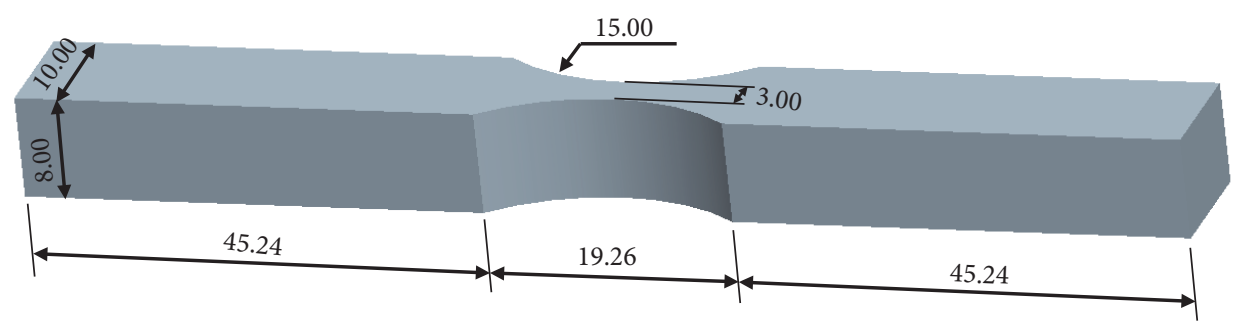

(b)

FIGURE 1: The design of the ultrasonic fatigue specimen in this test. (a) Schematic diagram of specimen sectioning; (b) dimensions of the ultrasonic fatigue specimen.

peak temperature is lower and the thermal cycle is shorter compared to the top. The rapid cooling experienced by the weld root effectively retards the grain growth and results in smaller recrystallized grains.

3.2. Microhardness Profiles. The microhardness on the cross section of the weld in the transverse direction was measured using a hardometer (force: $0.98 \mathrm{~N}$ and dwell time: $15 \mathrm{~s}$ ), and its distribution is shown in Figure 3(a). It is clear that the hardness distribution exhibits a "W" shaped profile, and softening around the weld center can be observed due to the coarsening and dissolution of strengthening precipitates during FSW process. The hardness in the HAZ decreases towards the weld center, while the TMAZ containing elongated grains was slightly strengthened by the intense plastic deformation as compared to the HAZ. Therefore, the minimum hardness value is located around the boundary between the TMAZ and $\mathrm{HAZ}$ at the advancing side. In the NZ, fine and equiaxed grains bring a recovery of hardness according to Hall-Petch relationship [20], but the values stay still below the level of BM. In detail, the hardness profile within the NZ along the thickness direction is also presented in Figure 3(b), in which an increasing trend can be observed from the top to bottom of the weld. This is in accordance with the variation tendency of grain size in the NZ. Moreover, it should be noted that the distribution of strengthening precipitates is another key factor to control the hardness beside grain size, because the coarsening and dissolution of precipitates are also nonuniform after the thermal cycle during FSW process [2123]. The hardness at the top shows much lower values than those near to the bottom, which is assumed to be caused by comparably high local temperature during strong plastic deformation. Therefore, the microstructural differences could result in a homogeneous response of hardness and other mechanical behaviors, indicating that the fatigue crack initiation is probably in association with local microstructure within the NZ.

3.3. S-N Curves. Fatigue results of all specimens in this test are shown in Figure 4, in which runout specimens at $10^{9}$ cycles are indicated with arrows. For comparison, the data of AA 7075 FSW joint obtained from the full specimen in our previous work are also presented [13], in which the fatigue failures occurred at the TMAZ in high cycle fatigue regime and at the NZ in the VHCF. It is clear that the fatigue strength keeps going down with cyclic load increasing. No fatigue limits can be observed for the NZ. As compared with the results of full specimens, the NZ exerts a better fatigue resistance than the TMAZ in high cycle fatigue range, explaining that fatigue failures were always located at the TMAZ when full specimens were tested. In VHCF regime, the fatigue strength of the NZ is still higher than that of the full specimen, even when the failures of full specimens occur at the NZ. This can be ascribed to the difference of specimen dimensions because the risk volume (specimen volume subjected to a stress amplitude larger than the $90 \%$ of its maximum value $[24,25])$ of the $\mathrm{NZ}$ specimen in this test is much smaller than that of the full specimen. Generally, a larger risk volume results in a smaller fatigue strength, so the fatigue behaviors of the NZ are slightly better in this test.

3.4. Fractography. Figure 5(a) presents typical appearances of the fracture surface. Different from general dog-bone shaped ultrasonic specimen with single crack origination, the fracture morphology in this test was characterized by multiple fatigue crack initiation sites occurring at the surface. This might be ascribed to the fact that the cross section of the specimen gauge $(3 * 8 \mathrm{~mm})$ is much larger than that of the general 


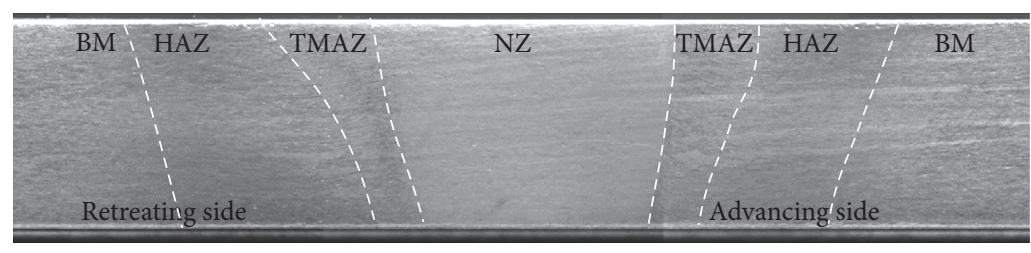

(a)
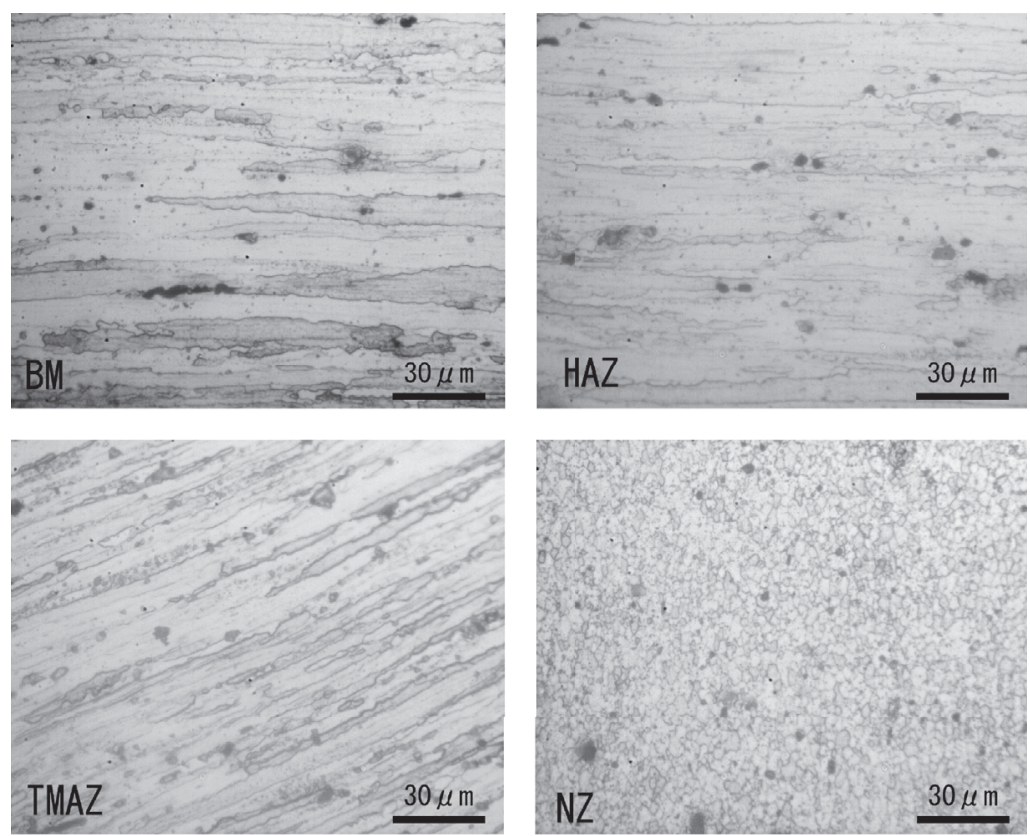

(b)

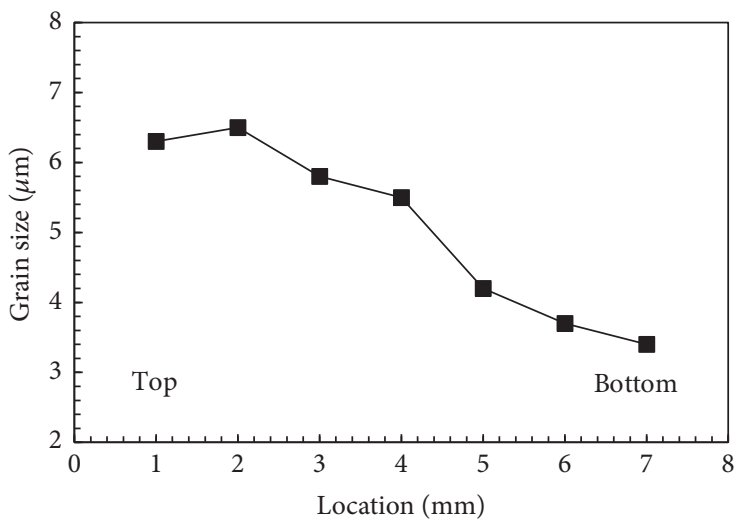

(c)

FIGURE 2: Optical micrographs of showing the microstructure along the cross section of (a) various microstructural zones, (b) enlarged view of each zone, and (c) variation of grain size in the NZ.

ultrasonic sample with only diameter of $3 \mathrm{~mm}$. As a result, the crack propagation process became longer under the same cyclic stress, which accordingly provided more opportunities for the formation of secondary fatigue crack. In addition, a special zone surrounding the fatigue crack initiation site could be identified for its different morphology as plotted with dash lines in Figures 5(b) and 5(c). In the enlarged view of fatigue crack initiation sites for different specimens as shown in Figure 6, it is clear that fatigue cracks were originated from welding defects (shrinkage porosity) located at the specimens. A cluster of recrystallized grains with diameters varying from 3 to $6 \mu \mathrm{m}$ can be clearly observed within the shrinkage porosity. It should be noted that particleinduced fatigue crack initiations were also detected twice in this test, but they were not the predominant factor to control the origination of fatigue crack. 


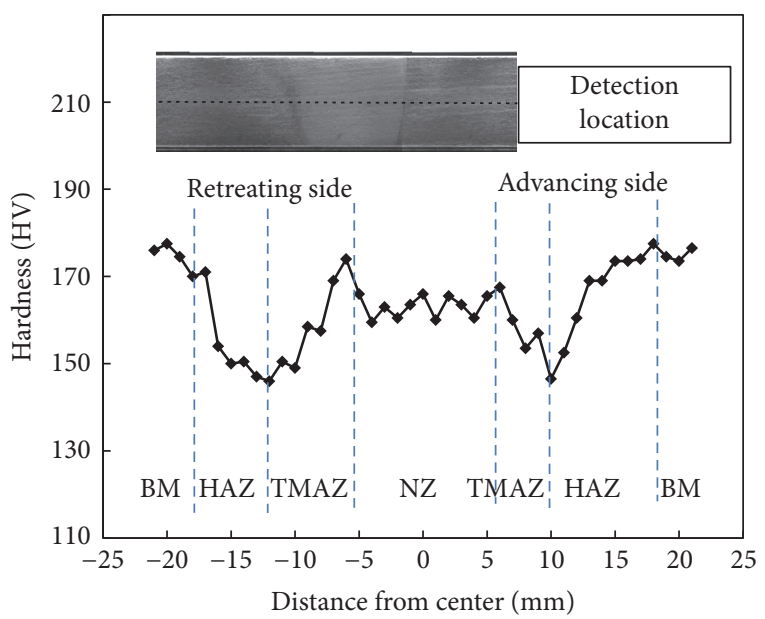

(a)

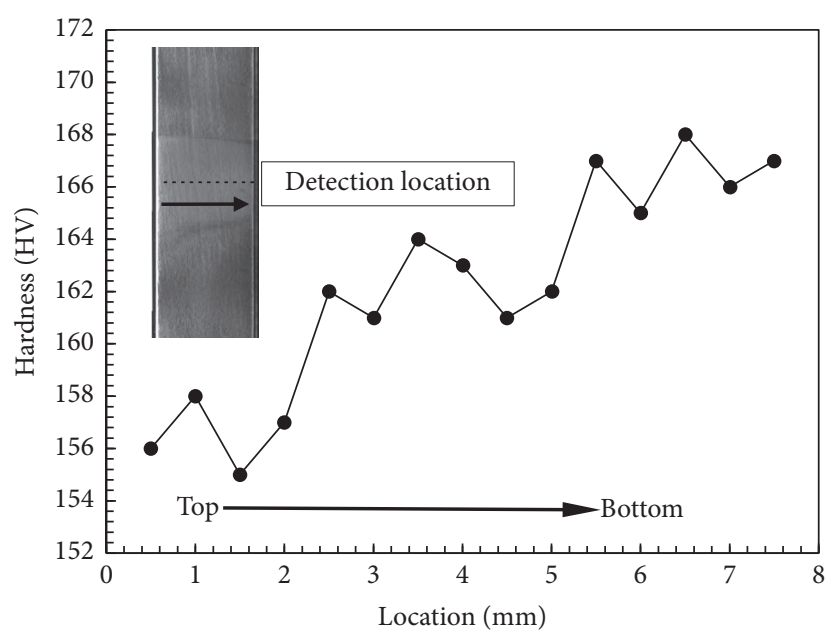

(b)

Figure 3: Hardness profiles on the cross section (a) in the transverse direction and (b) along the thickness direction in the NZ.

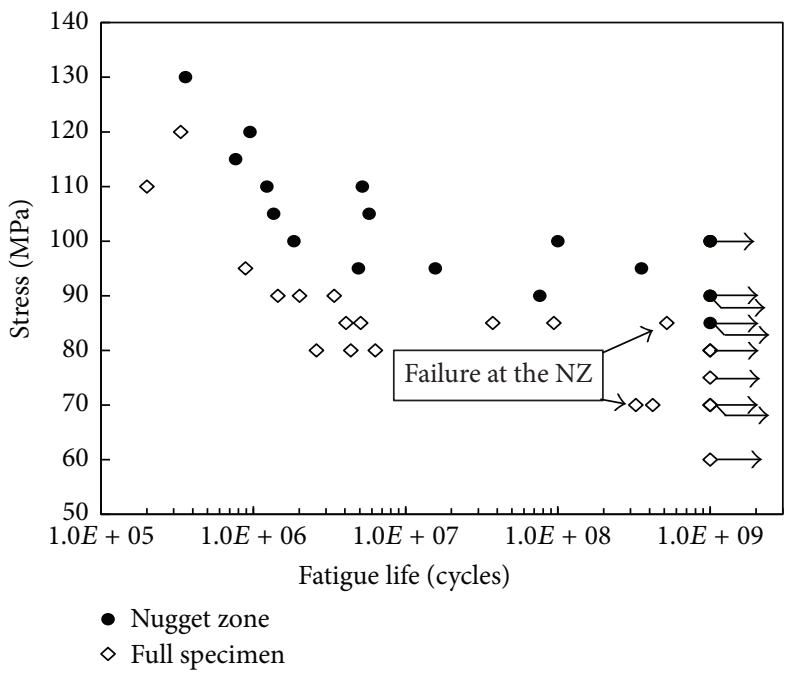

FIgURE 4: Relationship between the fatigue life and the stress amplitude for the fatigue testing results of the NZ.

\section{Discussions}

4.1. Fatigue Crack Propagation Threshold. A special semicircular zone embracing the fatigue crack initiation site has been detected as shown in Figure 5. Further observation found that the size of these zones was related to the fatigue life, as shown in Figure 7(a). It is found that the longer the fatigue life, the larger the special zone, which implies that a close association exists between the formation of the special zone and the fatigue process based on the fracture mechanics. Furthermore, the effective stress intensity factor $\Delta K$ at the periphery of the special zone was summarized for all failed specimens, based on the computing method of semicircular crack in infinite solid [26]. The results were provided in Figure 7(b), in which the experimental thresholds of fatigue crack propagation rate for 7XXX aluminum alloys obtained by some researchers [27-29] were also plotted for comparison. It can be seen that the values of effective stress intensity factor for the special zone almost keep constant with increasing the fatigue life. Besides, the effective stress intensity factor changes from 1.0 to $1.5 \mathrm{MPa} \sqrt{ } \mathrm{m}$, which is in good agreement with the fatigue crack propagation threshold. In other words, the formation of these zones was finished before the occurrence of a stable extended crack on the meaning of fracture mechanics. Similarly, the special morphology around the crack initiation site is also observed in the VHCF study of AA 6061 FSW joint [16], and it was reported that the formation of these zones consumes over $98 \%$ of total fatigue life in the VHCF range. The formation mechanism of the flat zones is still controversial and unclear. It has been confirmed that the fatigue crack initiation process and early crack extension are responsible for a major part of total fatigue life in the VHCF regime $[30,31]$.

4.2. Fatigue Crack Initiation Site. Generally, the welding processing significantly alters the local material properties; 


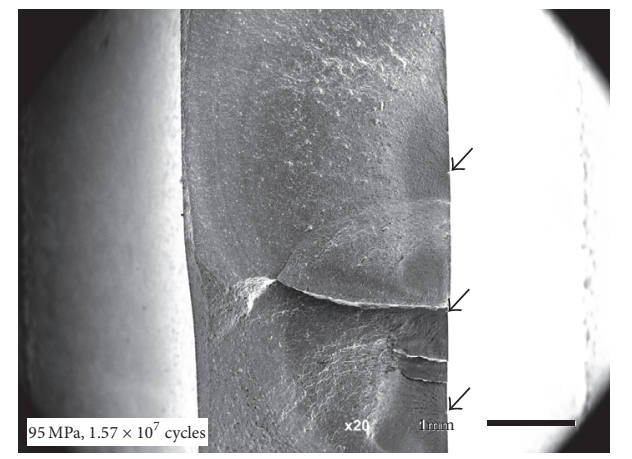

(a)

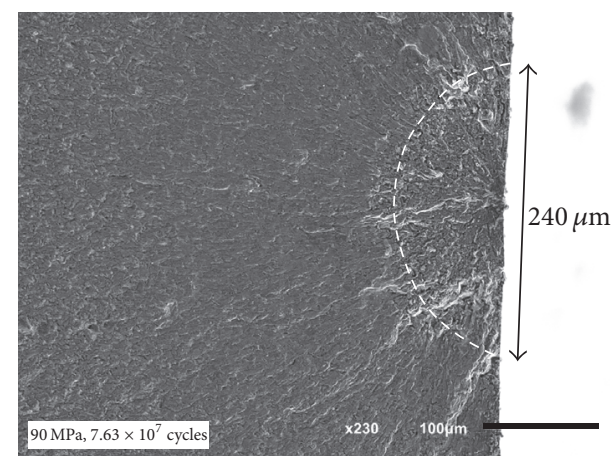

(b)

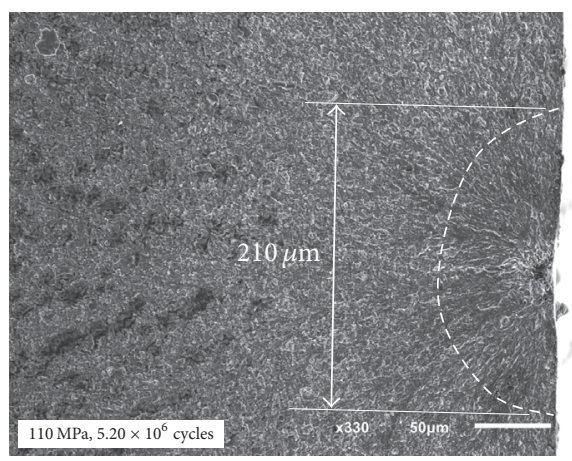

(c)

FIGURE 5: Typical fracture appearance of FSW joint with multiple crack initiation sites (a) and special semicircular morphologies located at the surface (b and $c)$.

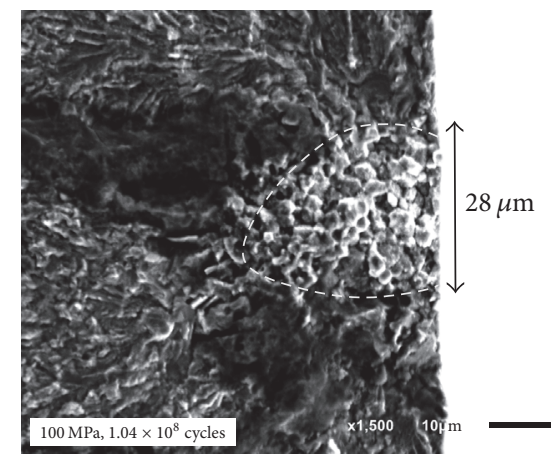

(a)

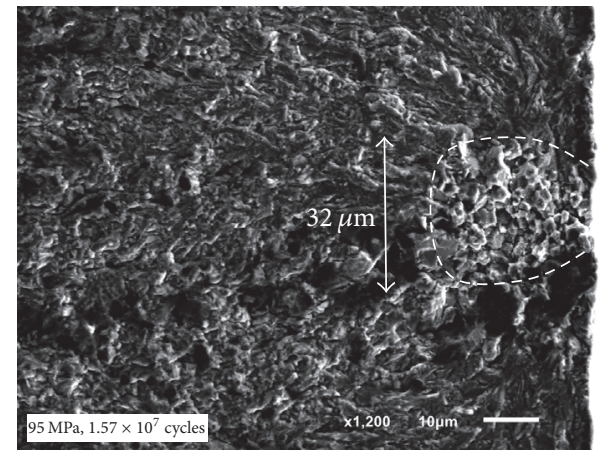

(b)

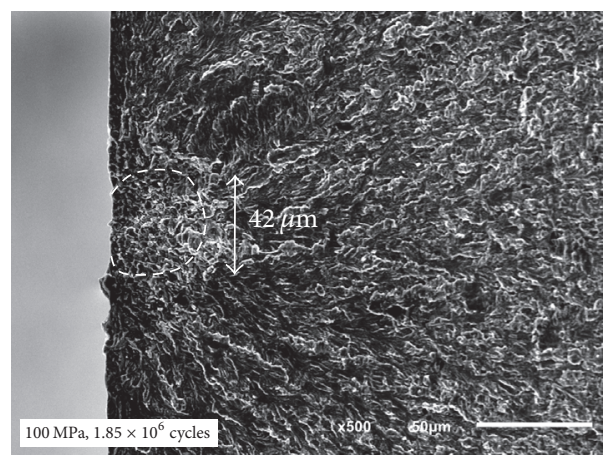

(c)

FIGURE 6: SEM micrographs of the fatigue crack initiation sites at specimen surface. 


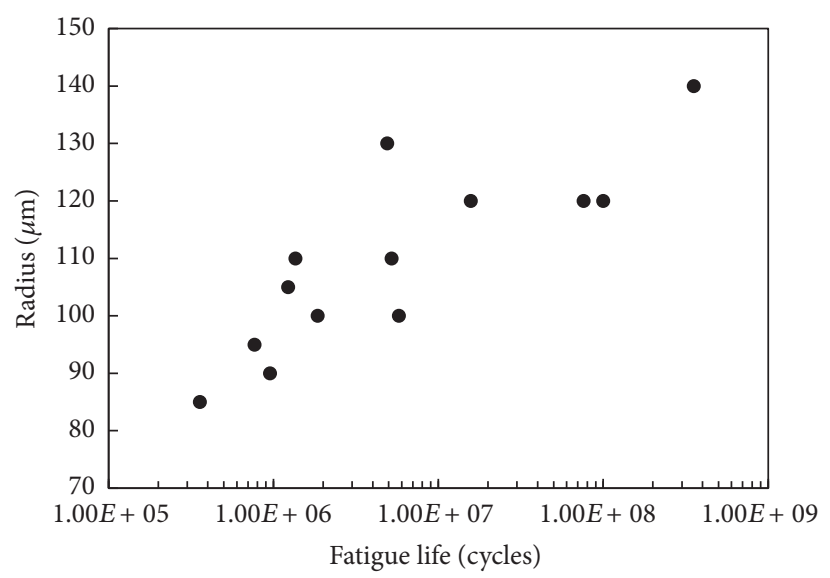

(a)

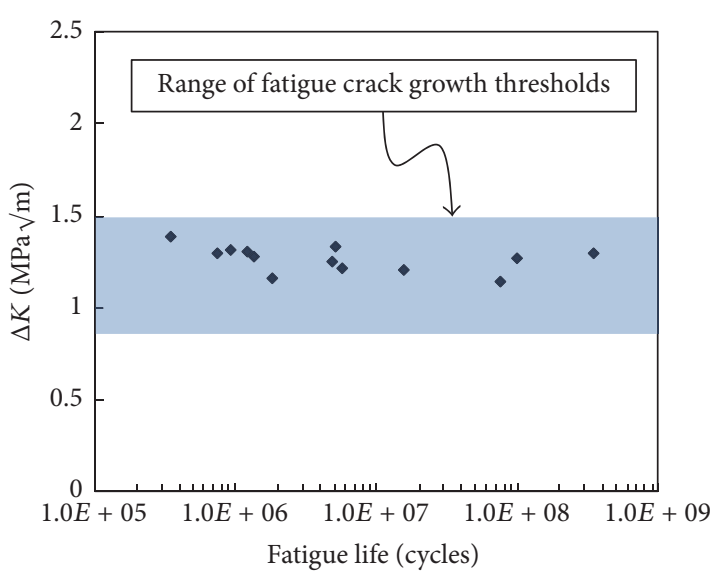

(b)

Figure 7: Analysis on the special semicircular zones: (a) radius variation versus fatigue life; (b) stress intensity factor range as a function of fatigue life.

hence the local mechanical behaviors are tied directly to the heterogeneous microstructure [32]. Accordingly, the resistance to fatigue crack initiation across the weld is also determined by local property distributions associated with the inhomogeneous structure [16]. In this test, the location of fatigue crack initiation site along with the fatigue life is presented in Figure 8(a). It is found that the majority of fatigue crack initiation sites are situated at the bottom of the NZ, and no clear regularities related to the fatigue lives can be observed. Therefore, the microstructural changes in grain size as shown in Figure 2(c) exert little influence on the mechanisms of fatigue crack initiation. This differs from the results of many previous studies that microstructural plasticity evolution in large grains generally initiates fatigue crack $[33,34]$. However, an area of shrinkage porosity has been detected at the crack initiation site as shown in Figure 6, indicating a close relationship between the formation of shrinkage porosity and the fatigue crack initiation. Generally, defects in FSW processing can be formed at higher rotation speeds and higher welding speeds due to the different temperature between the top part contacted with tool shoulder and the bottom part [35]. As a result, unsuitable parameters would cause welding defects located at the bottom of the weld more easily, because the top materials are applied with downforce by tool shoulder and accordingly the temperature is higher for a better flowability. Therefore, fatigue crack initiation sites are localized at the bottom of the NZ as presented in Figure 8(a). Moreover, it should be noted that the size of shrinkage porosity observed at the crack origination site is in the range of 20-40 um in diameter, which is much smaller than the size of visible flaws in regular defect detecting. These small defects have limited influence on tensile and fracture resistance but are the crucial factor to control fatigue crack initiation process in the VHCF range, because the VHCF failure became more sensitive to the small impurities and microstructural heterogeneities.

For a better understanding of the relationship between defects and fatigue life, the sizes of the shrinkage porosity along with the corresponding fatigue life are summarized in Figure 8(b), in which the projected area of the defect in the direction of maximum stress is calculated by assuming that the defect is shaped in semicircle located at the surface. Clearly, the size of defect decreased with the fatigue life increasing. It should be noted that the fatigue life is determined not only by the size of porosity but also by the amplitude of applied stress. However, the S-N curve in Figure 4 only presented the association between applied stress and fatigue life, but the effects of defect size on fatigue life are neglected. For high strength steels, some researchers had studied the effects of interior inclusions on the VHCF behavior in recent years [36-39]. However, the applicability of these models is doubtful for aluminum alloy welded joint with surface defects. Therefore, a new description of the relationship between welding defect size, applied cyclic stress, and fatigue life needs to be developed.

According to the work by Murakami and Usuki [40], a model has been developed for predicting the effect of defects on the fatigue strength. For the load ratio of $R=-1$, the fatigue limit $\sigma_{w}$ at high cycle fatigue regime can be obtained with the following empirical formula:

$$
\sigma_{w} \sqrt[n]{\text { Area }}=C
$$

where Area is the square root of the area obtained by projecting a defect onto the plane perpendicular to the loading stress and $n, C$ are constants. It should be noted that (1) was obtained and experimentally validated within high cycle fatigue regime. In this test, the S-N curve decreases constantly as shown in Figure 4, so there are no traditional fatigue limits. Here we suppose that the fatigue limit $\sigma_{w}$ was regarded as the fatigue strength at $10^{6}$ cycles. Therefore, (1) is thought to be still available for the prediction of fatigue strength at $10^{6}$ cycles in this test. When the applied stress $\sigma_{a}$ is above or below $\sigma_{w}$, the fatigue life would change accordingly. 


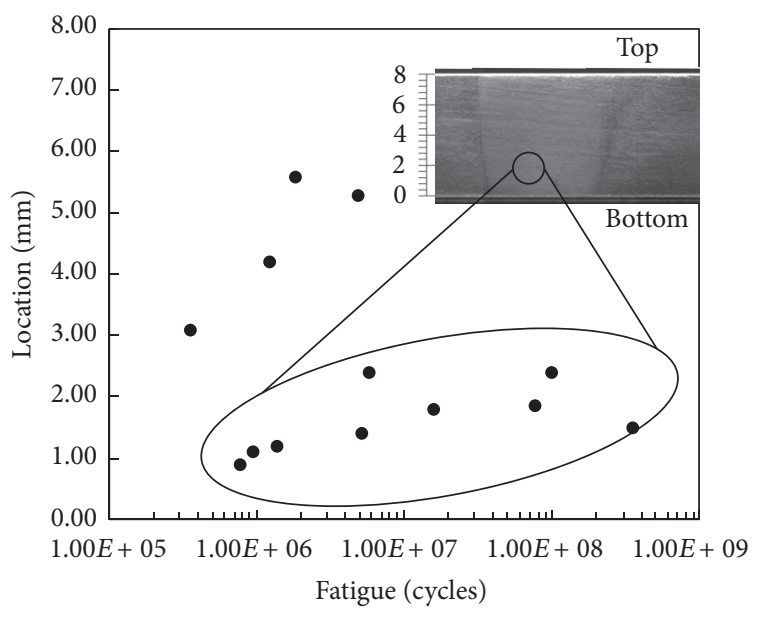

(a)

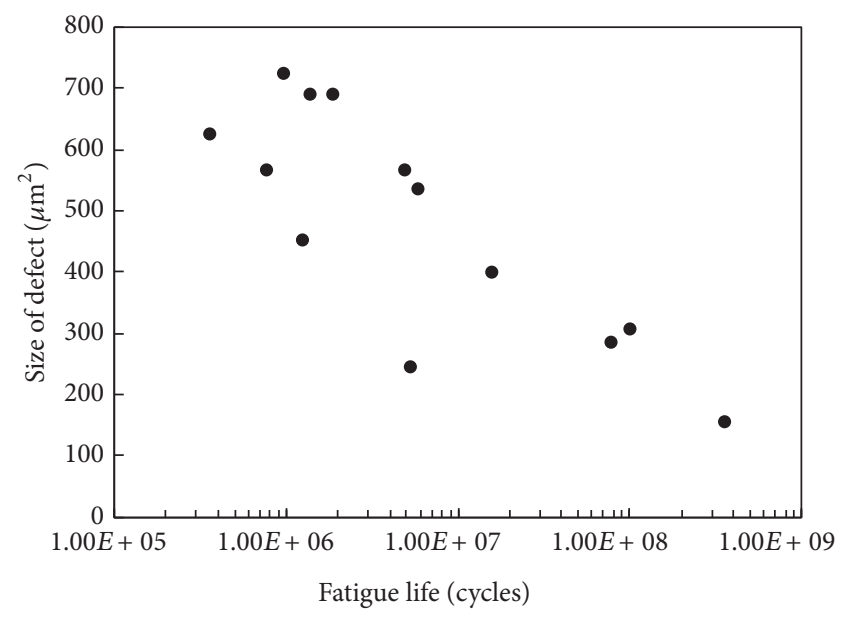

(b)

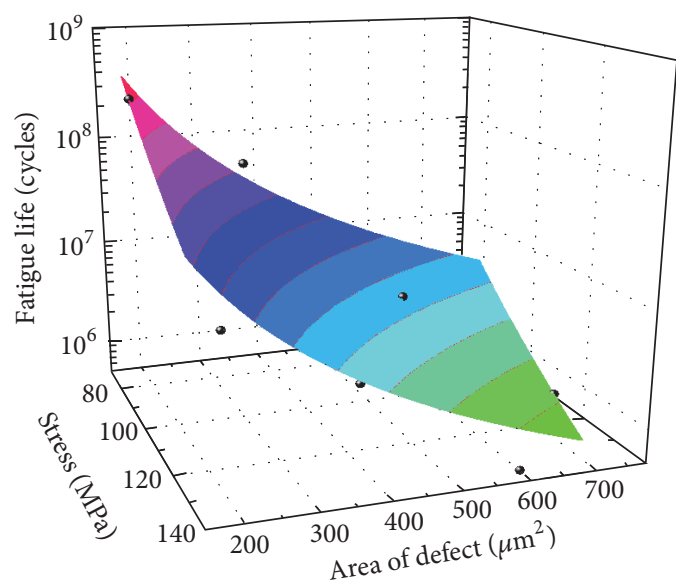

(c)

FIGURE 8: Analysis on fatigue crack initiation from the surface defect: (a) distribution of fatigue crack initiation sites in the NZ; (b) relationship between defect size and fatigue life; (c) calculated results of fatigue life considering applied stress and welding defect.

Taking into account the fatigue life, Murakami's model can be rewritten as the following expression:

$$
\sigma_{a} \sqrt[n]{\text { Area }}=f\left(N_{f}\right)
$$

where $f\left(N_{f}\right)$ is a function related to the fatigue life. Note that $\sqrt[n]{\text { Area }}$ varies within a very small range, so it is thought that the function $f\left(N_{f}\right)$ can be expressed approximately by using Basquin's equation:

$$
\sigma_{a} \sqrt[n]{\text { Area }}=\sigma_{f}^{\prime}\left(2 N_{f}\right)^{b}
$$

where $\sigma_{f}^{\prime}$ is fatigue strength coefficient and $b$ is Basquin exponent. For the convenience of comparison, we rearrange the expression as follows:

$$
\sigma_{a}=\sigma_{f}^{\prime}(\sqrt{\text { Area }})^{-1 / n}\left(2 N_{f}\right)^{b} .
$$

It can be seen that the models proposed by Tanaka and Akiniwa [36], Chapetti et al. [37], and Mayer et al. [38] are the special cases of the present model as (4). Using least square fitting, the approximation of fatigue life delivers the values of constants: $\sigma_{f}^{\prime}=5.92 \times 10^{9}, n=18.77$, and $b=$ -0.348 . The comparison between the calculated values of fatigue life and experimental results was shown in Figure 8(c). It is clear that the predicted fatigue life is in agreement with the experimental one, indicating that this model is capable of correlating the weld defect size, applied stress amplitude, and fatigue life.

\section{Conclusions}

Ultrasonic fatigue testing system was utilized to investigate very high cycle fatigue behaviors of nugget zone in AA 7075 FSW joint in the present work. The conclusions can be summarized as follows:

(1) Fatigue strength of the nugget zone decreased continuously in very high cycle regime with no horizontal platforms in the S-N curves. The nugget zone shows better fatigue resistance than that of the thermomechanically affected zone. 
(2) Fatigue crack initiated from the specimen surface and was surrounded by a special semicircular zone. The stress intensity factor of the special zone was equal to the threshold value of fatigue crack propagation rate, indicating that the formation of this zone consumes most of the total fatigue life.

(3) Shrinkage porosity located around the bottom side of the NZ determined the fatigue crack initiation site. A model was proposed for predicting the fatigue life of defect induced crack initiation, which takes into account the effect of defect size and applied stress. The predicted results are in good agreement with the experimental data in this work.

\section{Conflicts of Interest}

The authors declare that they have no conflicts of interest.

\section{Acknowledgments}

This research was financially supported by the National Natural Science Foundation of China (no. 11572057 and no. 11602038), and the support of JSPS Postdoctoral Fellowship for Overseas Researchers (P16809) is very much appreciated.

\section{References}

[1] J. G. Kaufman and E. L. Rooy, "Aluminum alloy castings: properties, processes, and applications," Asm International, 2004.

[2] E. A. Starke Jr. and J. T. Staley, "Application of modern aluminum alloys to aircraft," Progress in Aerospace Sciences, vol. 32, no. 2-3, pp. 131-172, 1996.

[3] R. Ashton, R. Wesley, and C. Dixon, "The effect of porosity on 5086-H116 aluminum alloy welds," Welding Journal, vol. 54, no. 3, 1975.

[4] S. Kou and Y. Le, "Grain structure and solidification cracking in oscillated arc welds of 5052 aluminum alloy," Metallurgical Transactions A, vol. 16, no. 7, pp. 1345-1352, 1985.

[5] W. Thomas, International patent application no. 1991, PCT/GB92/02203 and GB patent application.

[6] R. S. Mishra and Z. Y. Ma, "Friction stir welding and processing," Materials Science and Engineering: A Structural Materials: Properties, Microstructure and Processing, vol. 50, no. 1-2, pp. 178, 2005.

[7] C. G. Rhodes, M. W. Mahoney, W. H. Bingel, R. A. Spurling, and C. C. Bampton, "Effects of friction stir welding on microstructure of 7075 aluminum," Scripta Materialia, vol. 36, no. 1, pp. 69-75, 1997.

[8] R. Nandan, T. DebRoy, and H. K. D. H. Bhadeshia, "Recent advances in friction-stir welding-process, weldment structure and properties," Progress in Materials Science, vol. 53, no. 6, pp. 980-1023, 2008.

[9] Q. Y. Wang, N. Kawagoishi, and Q. Chen, "Fatigue and fracture behaviour of structural Al-alloys up to very long life regimes," International Journal of Fatigue, vol. 28, no. 11, pp. 1572-1576, 2006.

[10] C. Wang, D. Wagner, and C. Bathias, "Investigations on the fatigue crack propagation threshold in very high cycle fatigue," Advanced Materials Research, vol. 891-892, pp. 357-362, 2014.
[11] C. Deng, H. Wang, B. Gong, X. Li, and Z. Lei, "Effects of microstructural heterogeneity on very high cycle fatigue properties of 7050-T7451 aluminum alloy friction stir butt welds," International Journal of Fatigue, vol. 83, pp. 100-108, 2016.

[12] C. He, K. Yang, Y. Liu, Q. Wang, and M. Cai, "Improvement of very high cycle fatigue properties in an AA7075 friction stir welded joint by ultrasonic peening treatment," Fatigue \& Fracture of Engineering Materials \& Structures, vol. 40, no. 3, pp. 460-468, 2017.

[13] C. He, Y. Liu, J. Dong, Q. Wang, D. Wagner, and C. Bathias, "Fatigue crack initiation behaviors throughout friction stir welded joints in AA7075-T6 in ultrasonic fatigue," International Journal of Fatigue, vol. 81, pp. 171-178, 2015.

[14] G. Pouget and A. P. Reynolds, "Residual stress and microstructure effects on fatigue crack growth in AA2050 friction stir welds," International Journal of Fatigue, vol. 30, no. 3, pp. 463472, 2008.

[15] M. Muzvidziwa, M. Okazaki, K. Suzuki, and S. Hirano, "Role of microstructure on the fatigue crack propagation behavior of a friction stir welded Ti-6Al-4V," Materials Science and Engineering: A Structural Materials: Properties, Microstructure and Processing, vol. 652, pp. 59-68, 2016.

[16] C. He, Y. Liu, J. Dong, Q. Wang, D. Wagner, and C. Bathias, "Through thickness property variations in friction stir welded AA6061 joint fatigued in very high cycle fatigue regime," International Journal of Fatigue, vol. 82, pp. 379-386, 2016.

[17] R. I. Rodriguez, J. B. Jordon, P. G. Allison, T. Rushing, and L. Garcia, "Low-cycle fatigue of dissimilar friction stir welded aluminum alloys," Materials Science and Engineering: A Structural Materials: Properties, Microstructure and Processing, vol. 654, pp. 236-248, 2016.

[18] M. Besel, Y. Besel, U. Alfaro Mercado, T. Kakiuchi, and Y. Uematsu, "Fatigue behavior of friction stir welded Al-Mg-Sc alloy, International Journal of Fatigue, vol. 77, article no. 3526, pp. 1-11, 2015.

[19] C. Bathias, "Piezoelectric fatigue testing machines and devices," International Journal of Fatigue, vol. 28, no. 11, pp. 1438-1445, 2006.

[20] E. O. Hall, "The deformation and ageing of mild steel: III discussion of results," Proceedings of the Physical Society, Section $B$, vol. 64, no. 9, pp. 747-752, 1951.

[21] S. S. Yutaka, H. Hiroyuki, K. Ikeda, M. Enomoto, S. Jogan, and T. Hashimoto, "Microtexture in the friction-stir weld of an aluminum alloy," Metallurgical and Materials Transactions A: Physical Metallurgy and Materials Science, vol. 32, no. 4, article no. 351, pp. 941-948, 2001.

[22] P. L. Threadgill, A. J. Leonard, H. R. Shercliff, and P. J. Withers, "Friction stir welding of aluminium alloys," International Materials Reviews, vol. 54, no. 2, pp. 49-93, 2013.

[23] P. Dong, H. Li, D. Sun, W. Gong, and J. Liu, "Effects of welding speed on the microstructure and hardness in friction stir welding joints of 6005A-T6 aluminum alloy," Materials and Corrosion, vol. 45, pp. 524-531, 2013.

[24] Y. Furuya, "Specimen size effects on gigacycle fatigue properties of high-strength steel under ultrasonic fatigue testing," Scripta Materialia, vol. 58, no. 11, pp. 1014-1017, 2008.

[25] Y. Furuya, "Notable size effects on very high cycle fatigue properties of high-strength steel," Materials Science and Engineering: A Structural Materials: Properties, Microstructure and Processing, vol. 528, no. 15, pp. 5234-5240, 2011. 
[26] F. W. Smith, A. F. Emery, and A. S. Kobayashi, "Stress Intensity Factors for Semicircular Cracks: Part 2-Semi-Infinite Solid," Journal of Applied Mechanics, vol. 34, no. 4, p. 953, 1967.

[27] S. C. Forth, J. C. Newman Jr., and R. G. Forman, "On generating fatigue crack growth thresholds," International Journal of Fatigue, vol. 25, no. 1, pp. 9-15, 2002.

[28] T. L. Mackay, "Fatigue crack propagation rate at low $\Delta \mathrm{K}$ of two aluminum sheet alloys, 2024-T3 and 7075-T6," Engineering Fracture Mechanics, vol. 11, no. 4, pp. 753-761, 1979.

[29] P. C. Paris, H. Tada, and J. K. Donald, "Service load fatigue damage-a historical perspective," International Journal of Fatigue, vol. 21, no. 1, pp. S35-S46, 1999.

[30] Z. Wei, S. Lin, L. Luo, and L. Gao, "Components durability, reliability and uncertainty assessments based on fatigue failure data," SAE International Journal of Materials and Manufacturing, vol. 8, no. 1, pp. 80-90, 2014.

[31] Y. Hong, Z. Lei, C. Sun, and A. Zhao, "Propensities of crack interior initiation and early growth for very-high-cycle fatigue of high strength steels," International Journal of Fatigue, vol. 58, pp. 144-151, 2014.

[32] W. D. Lockwood and A. P. Reynolds, "Simulation of the global response of a friction stir weld using local constitutive behavior," Materials Science and Engineering: A Structural Materials: Properties, Microstructure and Processing, vol. 339, no. 1-2, pp. 35-42, 2003.

[33] C. He, R.-H. Tian, Y.-J. Liu, J.-K. Li, and Q.-Y. Wang, "Ultrasonic fatigue damage behavior of $304 \mathrm{~L}$ austenitic stainless steel based on micro-plasticity and heat dissipation," Journal of Iron and Steel Research, International, vol. 22, no. 7, pp. 638-644, 2015.

[34] C. Müller-Bollenhagen, M. Zimmermann, and H.-J. Christ, "Very high cycle fatigue behaviour of austenitic stainless steel and the effect of strain-induced martensite," International Journal of Fatigue, vol. 32, no. 6, pp. 936-942, 2010.

[35] Y. G. Kim, H. Fujii, T. Tsumura, T. Komazaki, and K. Nakata, "Three defect types in friction stir welding of aluminum die casting alloy," Materials Science and Engineering: A Structural Materials: Properties, Microstructure and Processing, vol. 415, no. 1-2, pp. 250-254, 2006.

[36] K. Tanaka and Y. Akiniwa, "Fatigue crack propagation behaviour derived from S-N data in very high cycle regime," Fatigue \& Fracture of Engineering Materials \& Structures, vol. 25, no. 8-9, pp. 775-784, 2002.

[37] M. D. Chapetti, T. Tagawa, and T. Miyata, "Ultra-long cycle fatigue of high-strength carbon steels part II: Estimation of fatigue limit for failure from internal inclusions," Materials Science and Engineering: A Structural Materials: Properties, Microstructure and Processing, vol. 356, no. 1-2, pp. 236-244, 2003.

[38] H. Mayer, W. Haydn, R. Schuller, S. Issler, B. Furtner, and M. Bacher-Höchst, "Very high cycle fatigue properties of bainitic high carbon-chromium steel," International Journal of Fatigue, vol. 31, no. 2, pp. 242-249, 2009.

[39] C. Sun, Z. Lei, J. Xie, and Y. Hong, "Effects of inclusion size and stress ratio on fatigue strength for high-strength steels with fisheye mode failure," International Journal of Fatigue, vol. 48, pp. 19-27, 2013.

[40] Y. Murakami and H. Usuki, "Quantitative evaluation of effects of non-metallic inclusions on fatigue strength of high strength steels. II: fatigue limit evaluation based on statistics for extreme values of inclusion size," International Journal of Fatigue, vol. 11, no. 5, pp. 299-307, 1989. 

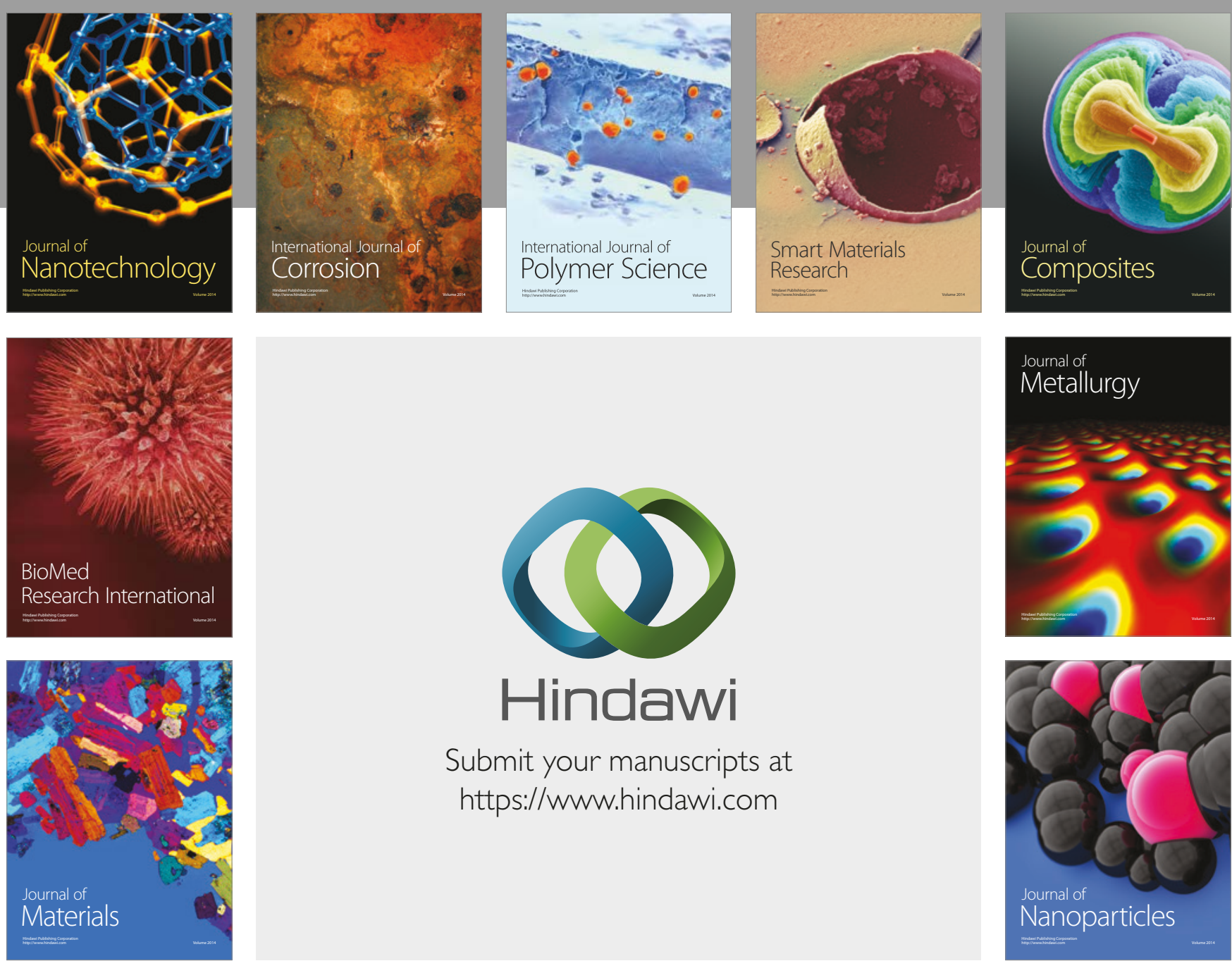

\section{Hindawi}

Submit your manuscripts at

https://www.hindawi.com
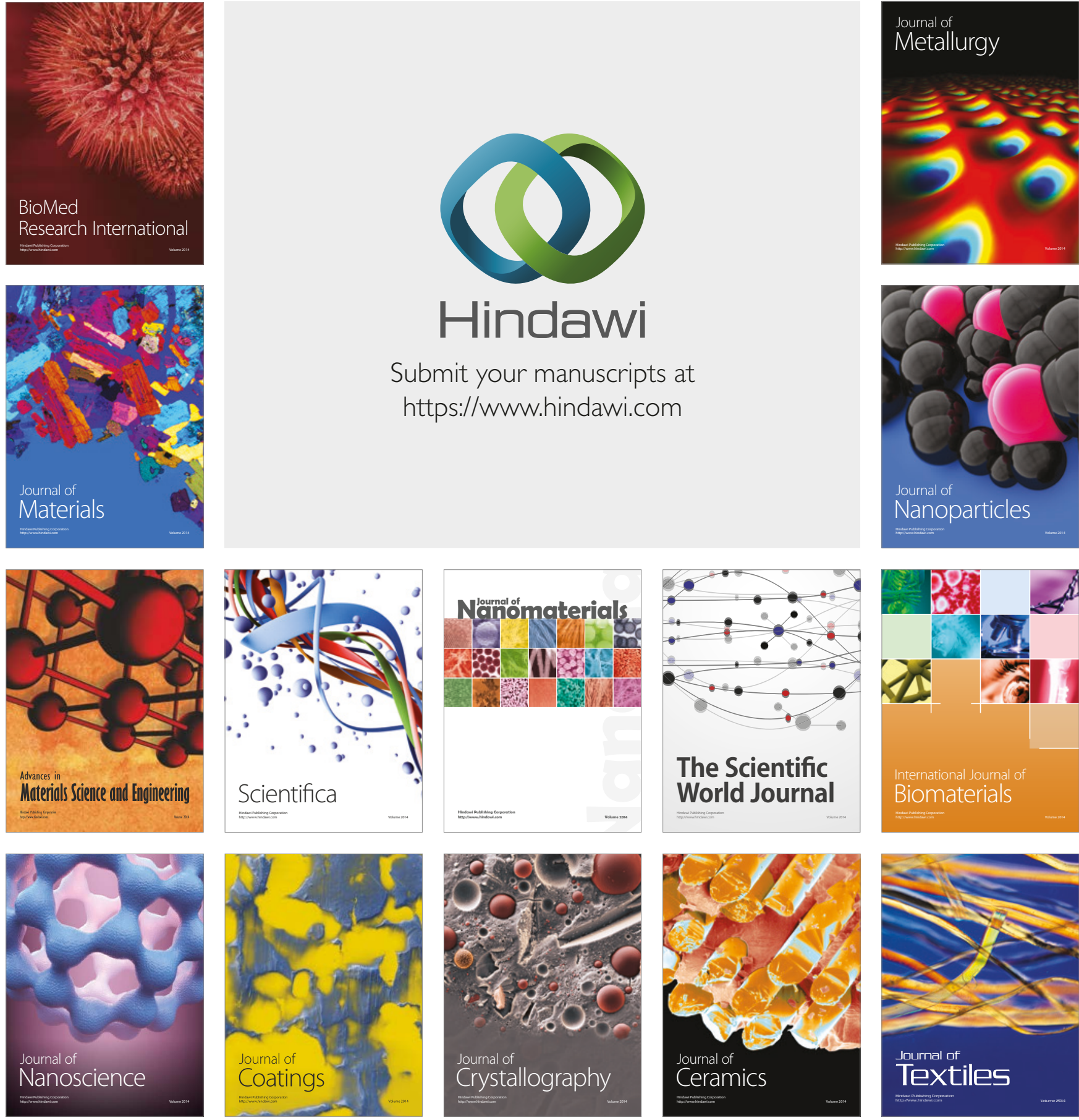

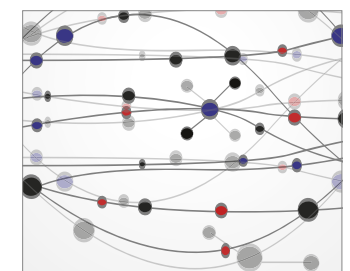

The Scientific World Journal
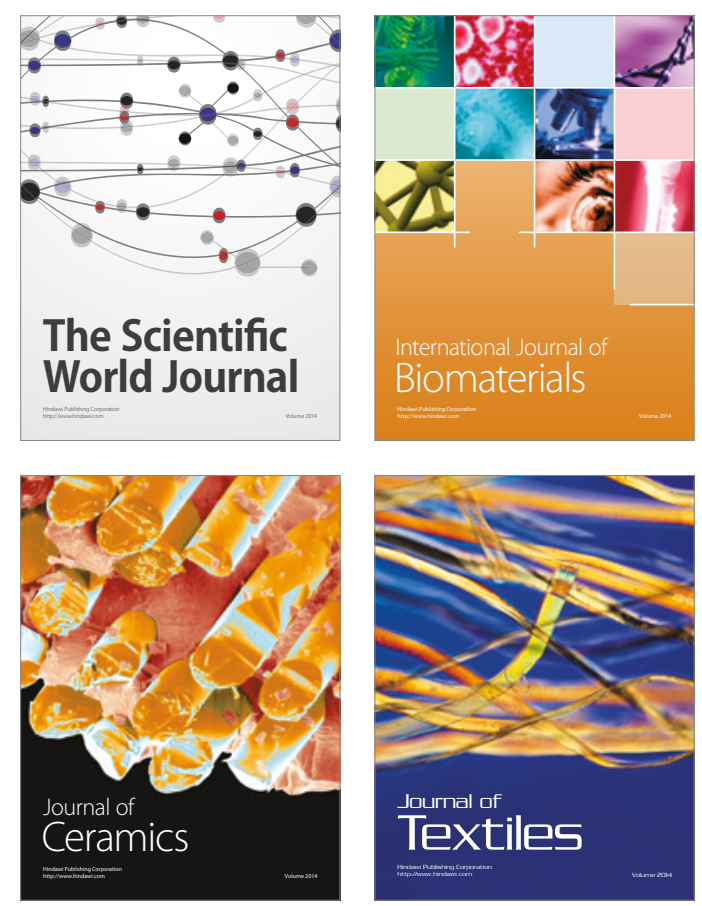